Cuadernos de Gobierno y Administración Pública ISSN: e-2341-4839

https://dx.doi.org/10.5209/cgap.65912

\title{
La nueva derecha radical como reto a la gobernanza y a la calidad de la democracia
}

David Lerín Ibarra ${ }^{1}$

Recibido: 7/04/2019 Aceptado: 04/05/2019

Resumen. El avance y consolidación electoral de las formaciones políticas de nueva derecha radical, en las últimas décadas, supone un reto para la calidad de la democracia occidental. Este fenómeno se ha extendido por prácticamente toda Europa, socavando los avances en la construcción de sociedades multiculturales y cosmopolitas, haciendo, por tanto, peligrar la diversidad social de las mismas. En este artículo de carácter teórico, tenemos como objetivo la conceptualización de estas formaciones, distinguiendo la extrema derecha de la nueva derecha radical por medio de un análisis comparativo entre ambas corrientes. De esta forma y siguiendo esta metodología, analizaremos dos principios ideológicos de estos partidos que suponen un riesgo para la gobernanza democrática: la defensa de la nación étnica y la palingenesia ultranacionalista.

Palabras clave: Derecha radical; nueva derecha radical; gobernanza; democracia; extrema derecha.

\section{[en] The new radical right as a challenge to governance and the democracy's quality}

\begin{abstract}
The electoral growing and consolidation of radical new right political organizations, in the last decades, represents a challenge for the quality of western democracy. This phenomenon has spread by practically all Europe, undermining the progress already done in the construction of multicultural and cosmopolitan societies, therefore endangering their social diversity. In this article of a theoretical nature, we have as objective the conceptualization of these formations, distinguishing the extreme right from the new radical right through a comparative analysis between both currents. In this way and following this methodology, we will analyze two ideological principles of these parties that pose a risk for democratic governance: defense of the ethnic nation and the palingenetic ultranationalism.
\end{abstract}

Keywords: Radical right; new radical right; governance; democracy; far right.

Sumario. 1. Introducción. 2. Conceptualización y clasificación 2.1 Diferenciación entre partidos fascistas y nueva derecha radical. 2.1.1. Partidos fascistas o extrema derecha. 2.1.2. Partidos de nueva derecha radical o derecha radical populista. 2.2. Criterios clasificatorios de la extrema derecha y de la nueva derecha radical. 3. Nación étnica según la nueva derecha radical y la extrema derecha. 4. Palingenesia ultranacionalista para la nueva derecha radical y la extrema derecha. 5. Reto a la gobernanza y a la calidad de la democracia. 6. Conclusión. Bibliografía.

Cómo citar: Lerín Ibarra, D., La nueva derecha radical como reto a la gobernanza y a la calidad de la democracia, en Cuadernos de Gobierno y Administración Pública 6-2, 93-116.

Universidad Complutense de Madrid
dlerin@ucm.es 


\section{Introducción}

En la actualidad, el estudio de la nueva derecha radical es de gran interés politológico debido al crecimiento o afianzamiento, en las últimas décadas, de un gran número de formaciones con esta ideología. En la mayoría de estados de Europa (Francia, Italia, Austria, Bélgica, Suiza, Países Bajos, Hungría, Dinamarca, Suecia, Finlandia o Noruega) encontramos partidos de nueva derecha radical que han emergido con un peso significativo. Su investigación es de gran relevancia, ya que sus principios y valores ideológicos suponen un reto claro a la gobernanza y a la calidad misma de la democracia.

Tras el final de la Segunda Guerra Mundial y la larga "travesía en el desierto" (Rodríguez Jiménez, 2006), desde finales de los ochenta y principios de los noventa, se va a ir produciendo una "contra-revolución silenciosa" (Ignazi, 1992), pero es ahora donde se va a dar un auténtica "ola populista" (Taguieff, 2007), o precisando, una oleada de derecha radical populista.

Para apreciar la importancia política de este fenómeno tan solo es necesario observar los resultados electorales de estas formaciones en los últimos años. El caso más paradigmático es el Front National (Frente Nacional francés) ${ }^{2}$, actualmente liderado por Marine Le Pen, que obtuvo un 21,3\% de porcentaje electoral y 7.679 .493 de votos en la primera vuelta en las presidenciales de 2017. Incluso, superó este nivel en la segunda vuelta en la que logró el apoyo del 33,90\% del electorado y 10.644 .118 de votos.

Pero este proceso no es un caso aislado, mencionemos otras cifras electorales de partidos de Europa Occidental ${ }^{3}$ de este espacio ideológico: Freiheitliche Partei Österreichs (FPÖ, Partido de la Libertad de Austria) consiguió el 26\% del electorado en las legislativas de 2017; Vlaams Belang (Interés Flamenco) llegó a tener el 24,2 \% de porcentaje electoral en las municipales de 2004; Lega Nord (Liga Norte Italiana) alcanzó el 17,37\% de los sufragios en las elecciones generales de 2018; Union Démocratique du Centre (UDC, Unión Democrática de Centro de Suiza) conquistó el 29,4\% de los votos en las legislativas de 2015; por su parte Partij voor de Vrijheid (PVV, Partido por la Libertad) obtuvo un 13,1\% en las elecciones de 2017 a la Cámara de Representantes de los Países Bajos (Tabla 1).

2 En 2018, ha cambiado su denominación por Agrupación Nacional (en francés, Rassemblement national, $\mathrm{RN}$ ), sin embargo, seguimos usando la nomenclatura Frente Nacional hasta que se asiente la nueva terminología.

3 De gran significado es el resultado de la derecha radical en la Europa Septentrional, esto es, en los países nórdicos: el Partido Popular Danés obtuvo el 21,1\% en las elecciones parlamentarias de Dinamarca de 2015; Demócratas de Suecia alcanzó el 12,9\% de votos en 2014 en el Parlamento sueco; Verdaderos Finlandeses logró un 17,65\% de sufragios en el Parlamento nacional en 2015; el Partido del Progreso Noruego consiguió un 15,20\% en las legislativas de 2017.

También son relevantes los partidos de derecha radical y extrema derecha en la Europa Oriental, ejemplo de ello lo encontramos en la formación Jobbik (Movimiento por una Hungría Mejor) que se alzó con el 19,54\% de apoyo electoral en las elecciones a la Asamblea Nacional Húngara de 2018.

El caso Griego también es interesante, donde un partido de extrema derecha con una ideología nacional-socialista, Chrysí Avgí (Amanecer Dorado), consiguió el 9,4\% de los votos en las elecciones al Parlamento Europeo de 2014. 
Tabla 1: Clasificación de partidos de extrema derecha y nueva derecha radical de Europa.

\begin{tabular}{|l|l|c|c|c|c|l|}
\hline \multicolumn{1}{|c|}{ Países } & \multicolumn{1}{|c|}{ Partido } & Siglas & $\begin{array}{c}\text { Escala } \\
\text { Lubbers }\end{array}$ & $\begin{array}{c}\text { Año } \\
\text { Elecciones }\end{array}$ & \% Votos & Tipo Elecciones \\
\hline Alemania & $\begin{array}{l}\text { Partido Nacional } \\
\text { Demócrata Alemán }\end{array}$ & NPD & $9,6^{5}$ & 2014 & $1,00 \%$ & EUROPEAS \\
\hline Austria & $\begin{array}{l}\text { Partido de la Libertad de } \\
\text { Austria }\end{array}$ & FPÖ & ---- & 2017 & $26,00 \%$ & PARLAMENTARIAS \\
\hline Bélgica & Interés Flamenco & VB & ---- & 2014 & $3,67 \%$ & PARLAMENTARIAS \\
\hline Bielorrusia & $\begin{array}{l}\text { Partido Liberal-Demócrata } \\
\text { de Bielorrusia }\end{array}$ & LDPB & 9,6 & 2016 & $4,24 \%$ & PARLAMENTARIAS \\
\hline Dinamarca & Partido Popular Danés & DF & 9,2 & 2015 & $21,10 \%$ & PARLAMENTARIAS \\
\hline España & Falange & FE & 9,6 & 2016 & $0,00 \%$ & PARLAMENTARIAS \\
\hline Finlandia & Verdaderos Finlandeses & VF & $9,1^{6}$ & 2015 & $17,65 \%$ & PARLAMENTARIAS \\
\hline Francia & Frente Nacional & FN & 9,6 & 2017 & $33,90 \%$ & PRESIDENCIALES \\
\hline Grecia & Amanecer Dorado & AFI & $9,7^{7}$ & 2014 & $9,40 \%$ & EUROPEAS \\
\hline Hungría & $\begin{array}{l}\text { Movimiento por Hungría } \\
\text { Mejor }\end{array}$ & JB & ---- & 2018 & $19,54 \%$ & PARLAMENTARIAS \\
\hline Italia & Casa Pound & CPI & $9,4^{8}$ & 2018 & $1,00 \%$ & PARLAMENTARIAS \\
\hline Italia & Liga Norte & LN & 8,3 & 2018 & $17,37 \%$ & PARLAMENTARIAS \\
\hline Noruega & $\begin{array}{l}\text { Partido del Progreso } \\
\text { Noruego }\end{array}$ & FrP & $8,7^{9}$ & 2017 & $15,20 \%$ & PARLAMENTARIAS \\
\hline Países Bajos & Partido por la Libertad & PVV & ---- & 2017 & $13,1 \%$ & PARLAMENTARIAS \\
\hline Rusia & $\begin{array}{l}\text { Partido Liberal-Demócrata } \\
\text { de Rusia }\end{array}$ & LDPR & 9,1 & 2016 & $13,14 \%$ & PARLAMENTARIAS \\
\hline Suecia & Demócratas Suecos & SD & 8,7 & 2015 & $12,90 \%$ & PARLAMENTARIAS \\
\hline Suiza & $\begin{array}{l}\text { Unión Democrática de } \\
\text { Centro }\end{array}$ & UDC & $9,3^{10}$ & 2015 & $29,40 \%$ & PARLAMENTARIAS \\
\hline
\end{tabular}

Fuente: Elaboración propia con datos oficiales de últimas elecciones publicadas a 1 de septiembre de 2018, principalmente parlamentarias (donde apreciamos menor sesgo electoral). Escala de Expertos Lubbers obtenida de Pippa Norris (2009: 73-77).

4 Escala combinada de opiniones de expertos Lubbers, siendo 0 la posición más a la izquierda y 10 la más a la derecha. En dicha escala, los partidos extrema derecha o derecha radical populista, para ser considerados como tal, tienen que obtener una puntuación igual o mayor que 8,0 .

5 Dato perteneciente a Deutsche Volksunion (DVU, Unión del pueblo Alemán) partido disuelto al unificarse al NPD, de análoga ideología.

6 Escala Lubbers de Sanmaallinen (Alianza Patriótica Nacional) de similar ideología a Perussuomalaiset.

7 Valoración alusiva a Eliniko Metopon (Frente Griego) idéntico en sus principios políticos a Amanecer Dorado.

8 Dato referido al movimiento neofascista Fiamma Tricolor (Llama Tricolor), gemelo ideológico de CasaPound, que es escisión del primero.

9 Escala de expertos Lubeers hace mención al Partido Patrio Noruego, disuelto en 2008, de análogo discurso político al Partido del Progreso, de hecho fue fundado por Harald Trefard, ex dirigente de esta última formación, donde fueron muchos de sus cuadros políticos.

10 Escala Lubbers de Démocrates Suisses (DS, Demócratas Suizos) que muestra unos principios ideológicos similares a Unión Démocratique du Centre. 
Todos estos datos nos muestran un claro avance o consolidación electoral de las formaciones políticas de derecha radical populista que se han extendido por prácticamente todos los parlamentos de la Europa Occidental, salvo algunas excepciones como Portugal o Irlanda. Además, encontramos otros países como Reino Unido o Alemania donde la politología no es unánime al ubicar a los partidos populistas existentes en la misma corriente que el resto de los europeos (Decker, 2016; Norris, 2009; Rodríguez-Aguilera de Prat, 2012 ${ }^{11}$.

Una de las causas del éxito de estos partidos, como vamos a estudiar en nuestra investigación, es la actualización de su discurso político diferenciándose de la extrema derecha que sigue anclada en su vinculación con el fascismo sin apenas renovación ideológica. Todas las formaciones de derecha radical populista, a pesar de su heterogeneidad, van a compartir elementos ideológicos similares. Como veremos, estos partidos defienden postulados teóricos basados en el etnonacionalismo (rechazando la inmigración, sobre todo la ilegal y la no asimilable) y en la recuperación de mitos ultranacionalistas pre-modernos que desequilibran valores democráticos actuales de los principales países de Europa.

Conjuntamente, como sostiene el politólogo francés Pascal Perrineau, este fenómeno va acompañado de una "lepenización de los espíritus", es decir, un proceso constante de cambio en las percepciones, en las ideas, en los sentimientos y en las conciencias de los individuos que de forma paulatina van asumiendo la crítica a sociedades multiculturales.

Por eso, este artículo de carácter teórico tiene como objetivo profundizar en la conceptualización y clasificación de la nueva derecha radical, distinguiéndola de la extrema derecha mediante un análisis comparativo entre ambas corrientes. Por tanto, pretendemos demostrar que el concepto de nueva derecha radical es diferente del concepto de extrema derecha. Para ello y siguiendo la metodología mencionada, se analizarán elementos diferenciadores entre las dos corrientes y profundizaremos en dos principios ideológicos básicos de estas formaciones que suponen un riesgo para la gobernanza democrática: la nación étnica y el ultranacionalismo palingenésico. $\mathrm{Y}$ de esta forma, pretendemos mostrar peculiaridades de ambos conceptos en torno a estas significativas cuestiones. Asimismo, con todo este análisis, y tras analizar otras investigaciones previas, queremos aportar una aclaración necesaria que ayude en la resolución de este "debate nominativo" (López Ortega, 2017: 37) o esta "guerra termológica" (De Lange \& Mudde, 2005) que sobre este tema existe.

11 Efectivamente, en estos países hay formaciones políticas de carácter populista en los que la ciencia política no es unánime en su categorización. Muchos politólogos indican que estos partidos estarían ubicados entre la nueva derecha radical y la derecha clásica conservadora. Por ejemplo, el catedrático Rodríguez-Aguilera del Prat (2012, p. 76) ubica United Kingdom Independence Party (UKIP) como "derecha radical" pero reconoce que "no ha tenido antecedentes neofascistas ni defiende un programa etnicista" y este último elemento es un principio central de la ideología de la nueva derecha radical. En parecido sentido, se pronuncia Pippa Norris (2009, p. 294) explicando que UKIP "carece de un contenido abiertamente racista".

Fenómeno muy similar lo encontramos en Alternativa por Alemania (AfD, Alternative für Deutschland) que de hecho pertenece al mismo grupo político que UKIP en el Parlamento Europeo (Grupo Europa de la Libertad y de la Democracia Directa). Por tanto, podría ser más conveniente ubicar a ambos partidos en la derecha populista, como define Frank Decker a AfD (Decker, 2016), pero sería cuestionable aplicar el término "radical" en su conceptualización, sobre todo por no tener un discurso marcadamente etnicista, al menos programáticamente, en la actualidad. 


\section{Conceptualización y clasificación}

Sobre el objeto de estudio, se ha utilizado diversa terminología para referirse al mismo fenómeno. Por lo que nos vamos a detener a analizar la denominación más apropiada para nuestra investigación.

Los partidos políticos de la nueva derecha radical usan una nomenclatura difusa, ambigua, neutra o de amplio calado popular para nombrarse a sí mismos, eliminando cualquier denominación que pudiera entenderse como "extremista" 12 y evitando normalmente cualquier término referente al fascismo o que le relacione a él. Por su parte, los grupos de la extrema derecha no son tan ambiguos en su denominación, ni en su posición ideológica, mostrando una clara vinculación con el fascismo clásico.

Por tanto, el problema definitorio que nos atañe es menos significativo en la (vieja) extrema derecha que en los partidos de nueva derecha radical, por lo que nos vamos a detener en el problema del esclarecimiento terminológico de estos últimos.

En general, se han usan expresiones diversas para denominarlos, pero algunos de esos términos no nos sirven para comprender de forma holística a todos estos partidos, sino que solo definirían a parte de ellos. Por este motivo, debemos rechazar cualquier terminología reduccionista del fenómeno investigado. Comprimir su conceptualización a un componente ideológico no es conveniente para definirlos con exactitud y objetividad. Efectivamente, no podemos caracterizar a toda la nueva derecha radical con una única característica programática de los mismos, aunque sea muy relevante en su teorización política. Por tanto, se deben descartar nomenclaturas reduccionistas como "ultrarreaccionarios", "étnicos", "anti-inmigración, "ultraconservadores", "nacionalistas", "autoritarios", "antigobierno" o "antisistema".

El concepto "neoliberal" tampoco es adecuado para denominar a todos los partidos de la nueva derecha radical, ya que un parte importante de ellos defienden postulados cercanos al proteccionismo económico, y la gran mayoría de ellos reivindica "la preferencia nacional" o el aumento de las "ayudas públicas a los nacionales".

De modo similar, no se pueden categorizar a estos partidos como "nueva derecha" o "neoconservadores", ya que tales conceptos hacen referencia a una ideología asociada a la defensa de la privatización, al libre mercado, a los recortes fiscales, al intervencionismo exterior, a la administración Bush y a figuras "neocons" importantes como Paul Wolfowitz, Richard Perle, Dick Cheney, Donald Rumsfeld o James Woolsey.

Asimismo, estos partidos niegan tener cualquier proximidad o relación con el fascismo histórico, así lo vemos en el Frente Nacional francés, en el Partido de la Libertad de Austria, en la Unión Democrática de Centro Suiza... En cambio, la extrema derecha sí mostrará vínculos con el fascismo clásico, como vemos en partidos como Amanecer Dorado o la Casa Pound italiana. Por consiguiente, descartamos los términos "fascistas", "nazis", "filofascistas", "filonazis", "neofascistas", "neonazis" o "criptofascistas" para designar a los partidos de nueva derecha radical.

De este modo, vamos a optar por la expresión "nueva derecha radical o derecha radical populista" para etiquetar a esta familia de partidos políticos, siguiendo a Cas Mudde (2007). Otros autores de ciencia política usarán conceptos parecidos: Daniel

12 Ejemplos claros los vemos en las siguientes nomenclaturas: "Libertad": Partido de la Libertad de Austria (FPÖ) o el Partido por la Libertad de los Países Bajos (PVV); "Demócrata": Demócratas de Suecia (S.D); "Progreso": Partido del Progreso Noruego (Prf); "Popular": Partido Popular Danés (DF); "Centro": Unión Democrático de Centro (UDC). 
Bell (1963) publica “The Radical Rigth" en 1963 usando este término para identificar a estas formaciones, al igual que Pippa Norris (2009) y Roger Griffin (2000) ${ }^{13}$; Miguel Ángel Simón (2007) describe esta ideología como "derecha radical contemporánea"; Joan Antón Mellón y Aitor Hernández-Carr (2016) nos habla de "derecha radical populista"; Hans-Georg Betz (2004) define esta corriente como "populismo de derecha radical".

Profundicemos en la conceptualización de Cas Mudde (2007), uno de los mayores investigares y referentes en el campo de las ciencias sociales en este campo. El profesor neerlandés explica que es necesario usar el término de "nueva derecha radical o derecha radical populista" para diferenciar dicho fenómeno conceptualmente del fascismo del que reniegan estas formaciones. Por tanto y como estamos comentando, estos grupos debemos distinguirlos de los partidos de extrema derecha que sí seguirán vinculados el fascismo histórico. Además, la nueva derecha radical tiene elementos propios que no tenía el fascismo como la reivindicación de la idea de "Europa"14, el populismo "anti establishment" o la sustitución de categorías racistas por la "diferenciación étnica".

Es cierto que la expresión "extrema derecha" también es usada por algunos investigadores sociales para analizar las actuales formaciones de derecha radical populista, pero la mayor parte de la politología no usa dicha expresión para definir a estos nuevos partidos. Por su parte, Piero Ignazi (2003) sí usa el término "extrema derecha" pero distingue, de forma análoga a Mudde, dos claras familias de partidos: "la vieja extrema derecha" vinculada al fascismo y "la nueva extrema derecha" no emparentada al fascismo clásico. Profundizaremos dicho análisis más adelante.

Para completar nuestro análisis, mencionamos el trabajo de Backes y Jesse (1984) que diferencian entre radicalismo y extremismo. El extremismo se opone a la democracia liberal, es anti-constitucional, anti-pluralista y anti-parlamentario. El radicalismo identificaría más una forma de acción o de actuación que puede ser o no antidemocrático.

De forma similar, Pippa Norris (2009: 65) describe la extrema derecha como "grupos que se encuentran mucho más allá de los límites legales de la política democrática y está dispuestos a emplear acción directa violenta o, incluso, tácticas terroristas". En cambio, los partidos de nueva derecha radical, según Roger Griffin (2000), aceptan el sistema liberal pero reclaman la expulsión, marginación o segregación de las personas que no son de la étnica autóctona, es decir propugnan un "liberalismo etnocrático".

\subsection{Diferenciación entre partidos fascistas y nueva derecha radical}

Debemos, por tanto, distinguir conceptualmente la "nueva derecha radical o derecha radical populista" de los grupos fascistas o "extrema derecha" (Mudde, 2007). Está categorización ha sido tomada por la mayoría de politólogos que investigan el fenómeno (Antón Mellón, et.al. 2011; Hernández-Carr, 2011), diferenciación análoga a la que

13 La profesora especializa en Europa del Este, Sabrina Ramet (2010), también usará el término "derecha radical” para agrupar a los partidos de esta ideología. Para la politóloga de la universidad de Washington estos grupos "comparten la intolerancia organizada".

14 Obviamente nos referimos a la "Europa de las patrias" o al "imperio europeo" (Benoist) y no la Unión Europea actual, de la que profesan un claro euroescepticismo o eurofobia, de diferente grado según el país o partido. 
nos muestra Piero Ignazi (2003) o José Luis Rodríguez Jiménez (2006) entre "vieja extrema derecha" y "nueva extrema derecha". Detengámonos, por tanto, en especificar las características de los partidos fascistas (o vieja extrema derecha) y de las formaciones de nueva derecha radical.

\subsubsection{Partidos fascistas o extrema derecha}

Los movimientos fascistas emergen a raíz de la crisis económica y sociopolítica que se produce tras la Primera Guerra Mundial en la Europa de entreguerras y quiebra del Estado liberal clásico. Ante dicha crisis, aparecen distintas salidas, principalmente los partidos comunistas y los partidos fascistas.

Estos últimos van a tener una base social de pequeña burguesía y clases medias pero que van a ser apoyados por las capas sociales más acomodadas en respuesta al crecimiento de los partidos socialistas y comunistas, que agrupaban principalmente a la clase trabajadora. Proponen acabar con la democracia parlamentaria, suprimir el pluralismo político y crear un Estado autoritario o totalitario encarnado en un líder carismático e indiscutido y una ideología nacionalista y militarista (Raschke, 1983).

Defienden una visón racial ${ }^{15}$ de la nación y un ultranacionalismo palingenésico con la misión de hacer renacer del pasado una época mítica de la nación, con referencias normalmente imperiales. Conceden enorme importancia a la significación del partido político, estableciendo dictaduras de partido único cuando toman el poder. Organizativamente, estas formaciones son una copia de los partidos de masas socialistas, consiguiendo en bastantes casos una gran movilización, además hacen énfasis en el control de la militancia y la militarización de la misma.

Históricamente, como sabemos, estos partidos adquirirán gran relevancia y poder en distintos países entre 1919 y 1949, sobre todo en Italia y Alemania. En un sentido estricto, la palabra fascismo se aplica para referirse sólo al partido italiano que, en su origen, lo acunó, pero se ha extendido para aplicarse a cualquier ideología política comparable. Incluso, democracias liberales históricas, como Francia (Partido Popular Francés) o Inglaterra (La Unión Británica de Fascistas), tuvieron grupos fascistas significativos durante las décadas de 1920 y 1930, del mismo modo hubo otros movimientos fascistas como el rexismo belga ${ }^{16}$, el jonsismo y falangismo español ${ }^{17}$, el Movimiento Nacional Socialista de los Países Bajos, la Cruz de Hierro en Rumania, la Cruz Flechada Húngara, la Unión Nacional de Noruega, Partido Nacional Socialista de los Trabajadores de Suecia o el Partido Nacional Socialista de Dinamarca.

Tras la Segunda Guerra Mundial, los partidos que reivindican el fascismo desaparecerán o serán irrelevantes políticamente, prácticamente ajenos a la vida parlamentaria de casi todos los países europeos. Los neofascistas o "extrema derecha"

15 Aunque la "raza" siempre va a estar presente en el discurso fascista desde sus inicios, llegarán a su máxima expresión con el ascenso al poder del Partido Nacionalsocialista alemán y la instauración por Mussolini de las leyes raciales desde 1938 en el estado italiano y posteriormente en la República de Saló (República Social Italiana).

16 El Partido Rexista (Christus Rex) fue un movimiento belga de origen católico, nacionalista y conservador, liderado por Leon Degrelle, que fue acercándose progresivamente al fascismo, como de forma análoga hizo falangismo español.

17 En España, el fascismo tiene su origen en las Juntas de Ofensiva Nacional Sindicalista (JONS) de Ramiro Ledesma y Onésimo Redondo que se fusionarán con Falange Española de José Antonio Primo de Rivera, impregnado este segundo grupo de un evidente fascismo europeo. 
(Mudde, 2007) son nostálgicos del periodo de entreguerras y exhiben revisionismo histórico, se muestran contrarios frontalmente a la Unión Europea pero reivindican la idea racial de Europa ("Europa blanca"), pretenden expulsar a todos los inmigrantes (legales e ilegales) y rechazan a minorías como los homosexuales y gitanos (Olascoaga, 2018). Por ende, siguen reivindicando una concepción de racial de la nación. Podemos citar ejemplo de estos partidos: Amanecer Dorado en Grecia (el partido de esta corriente más relevante actualmente), Movimiento Social Italiano (MSI), Casa Pound, o el Partido Nacional Demócrata Alemán (NPD). En España podemos mencionar a grupos muy minoritarios que profesar una ideología cercana al fascismo italiano, al nacional socialismo alemán, al jonsismo o al rexismo: Hogar Social, Acción Nacional Revolucionaria, Falange Española ${ }^{18}$, Movimiento Social Republicano, Estado Nacional Europeo, Alianza Nacional...

\subsubsection{Partidos de nueva derecha radical o derecha radical populista}

Los partidos de nueva derecha radical son grupos políticos organizados, que renegando del fascismo histórico, defienden un nacionalismo de base étnica y postulados autoritarios, populistas y nativistas.

Los partidos fascistas o neofascistas (extrema derecha), como acabamos de analizar, sostienen teorías raciales de la nación, en cambio la nueva derecha radical defiende la diferenciación cultural basada en principios étnicos, con una crítica dura a la inmigración ilegal o no asimilable. Además otra evidente novedad será un marcado populismo anti-establishment (anti élite política), por eso, estos grupos también reciben la denominación de "derecha radical populista", como hemos mencionado. De este modo, estos partidos quedan definidos por su "etno-nacionalismo y una retórica populista anti-establishment político", como especifica el profesor de sociología, Jens Rydgren (2005).

Consiguientemente, son nativistas, es decir diferencian a la población "originaria" del país de la "ajena" a la misma y, por tanto, rechazan la inmigración no asimilable étnicamente, sobre todo la islámica. Efectivamente, como analizamos más adelante, doctrinalmente defienden un concepto étnico de la nación, que ya no es racial como era en el fascismo, pero que rechaza frontalmente la nación cívica. Por tanto, la pertenencia a la nación no es libre ni voluntaria sino que viene marcada por una herencia compartida y rasgos culturales en común.

Del mismo modo, critican el estado decadente y corrupto en que se encuentra la nación en el momento actual, provocada por la globalización, el multiculturalismo, los partidos tradicionales, "el establishment" y "la élite política". Frente a ello reivindican, por ende, el renacimiento de un pasado glorioso y mítico de la misma (ultranacionalismo palingenésico) que también hemos citado como propio del fascismo y que desarrollaremos más adelante.

Importante también comentar que su apoyo electoral es interclasista pero haciendo especial incidencia en las capas sociales más vulnerables de la población nacional, incluso, en sectores que tradicionalmente habían apoyado a partidos socialistas o comunistas, intentando así ganar el voto de los "perdedores" de la glo-

18 El partido Falange Española (F.E) representaría el visón más fascista del falangismo actual. Otros partidos de esta corriente, como Falange Auténtica, se desvinculan claramente de estos principios. El partido hedillista, incluso, manifestará postulados opuestos al fascismo y al franquismo. 
balización o la integración europea (Rodríguez-Aguilera de Prat, 2012). Del mismo modo, tendrán apoyo de sectores de clase media temerosas de perder su "status quo", normalmente ex votantes de partidos conservadores que habrían cambiado su voto ante los fenómenos de emigración, inseguridad e identidad nacional (Ignazi, 2003).

Haciendo un pequeño repaso histórico, en los años cincuenta surgen partidos pequeño-burgueses, anti-impuestos: L'Uomo Qualunque (Un Hombre Cualquiera) y poujadismo ${ }^{19}$. Más tarde, con esta característica, surge en 1973 el Partido del Progreso Danés. A finales de los ochenta y principios de los noventa consiguen un auge electoral, "contra-revolución silenciosa" (Ignazi, 1992), por diversos motivos: neoconservadurismo, nueva polarización, crisis de la política tradicional, del sistema de partidos convencionales y del propio sistema político en su globalidad. A esto se le añade la crisis económica y sobre todo la inmigración que contribuye en gran medida a su éxito electoral.

Podemos, también, mencionar el "macartismo" como precedente de la nueva derecha radical, estudiado en un libro clásico de la politología: "The New American Right" de Daniel Bell. Como sabemos el macartismo se produjo en los años cincuenta del siglo pasado, durante el cual el senador republicano Joseph McCarthy desarrollo una serie de persecuciones, denuncias, investigaciones irregulares, acusaciones sin sustrato legal y listas negras contra cualquier persona sospechosa de ser comunista o realizar "actividades anti-americanas". Daniel Bell (1955) manifiesta que aunque hay elementos comunes, el macartismo y la derecha radical no son idénticos. La derecha radical es un movimiento que teme no solo al comunismo, sino a la modernidad. Esta crítica a la modernidad es de hecho un elemento doctrinal básico del fascismo (extrema derecha) y de buen parte de la nueva derecha radical.

Del mismo modo, es importante señalar el fenómeno políticos de Las Ligas italianas: la Liga Lombarda (Lega Lombarda), la Liga Veneta (Liga Véneta), Liga Norte Piamonte (Lega Nord Piemont) aglutinadas en Liga Norte (Lega Nord). Pertenecen a un movimiento, surgido en los ochenta, que manifestaba en un principio un ideario independentista, para el norte italiano (Padania), modificado después por planteamientos federalistas. Ideológicamente tiene una fuerte gran carga de populismo intentando enfatizar elementos de territorialidad, nacionalidad y anti-inmigración (Biorcio, 1992: 11).

En las últimas décadas, la nueva derecha radical se está consolidando y avanzando electoralmente en la mayoría de países europeos como hemos ejemplificado en la introducción, favorecidos por el fenómeno de la emigración, el terrorismo islámico, la crisis económica y el aumento del euroescepticismo. Sus valores ideológicos han cambiado y, sobre todo en los últimos años, han articulado una ideología más coherente que la existente tras el final de la Segunda Guerra Mundial, defendiendo la

19 Para analizar el Poujadismo francés es necesario conocer la obra "Le mouvement Poujade" de Stanley Hoffmann. Este movimiento, con gran apoyo pequeño burgués (comerciantes, artesanos, ganaderos, carniceros y libreros) muestra una defensa de la identidad y del nacionalismo francés, reivindicando la causa colonial francesa en Argelia. Además, exalta el moralismo, apela a las clases medias y manifiesta un claro rechazo a los impuestos, a la inmigración, a la integración europea, a la burocracia, a las grandes superficies, al intelectualismo y al parisinismo. (Hoffman y otros, 1962). Jean-Marie le Pen, fundador del Frente Nacional Francés, fue diputado poujadista en 1957. 
identidad y el nacionalismo europeo de raíces cristianas, superando la idea de estado-nación clásico. Aunque muestran diferencias, la mayoría de estos partidos tiene en común el ultranacionalismo étnico y palingenésico (como explicaremos más adelante), discurso anti-establishment contrario a las élites políticas, defensa de la soberanía nacional, proteccionismo económico ("preferencia nacional"), rechazo severo a la inmigración ilegal, euroescepticismo o eurofobia con la Unión Europea, conservadurismo moral, tradicionalismo, nativismo y defensa de una idea de nación primordialista.

Podemos citar evidentes ejemplos de estos partidos en Europa: Partido de la Libertad de Austria, Interés Flamenco, Liga Norte, la Unión Democrática de Centro de Suiza, Partido por la Libertad holandés, Verdaderos Finlandeses, Frente Nacional francés... En España en esta corriente nos encontramos a formaciones como España2000 (López Ortega, 2016), Plataforma Per Catalunya (Casals, 2009). También es importante citar el partido liderado por Santiago Abascal, Vox, fenómeno en reciente emergencia y todavía hoy en estudio y análisis.

\subsection{Criterios clasificatorios de la extrema derecha y nueva derecha radical}

Una de las principales formas para clasificar a estas formaciones políticas ha sido la realizada por el politólogo italiano Piero Ignazi (Ignazi 1992: 3-24), siguiendo tres criterios:

a. Criterio espacial (posicionamiento en el contínuum Izquierda - Derecha). Ignazi indica que estos partidos deben estar ubicados en el extremo derecho de la escala. Sin embargo, vemos que pocos de estos partidos se autoposicionan en el lado más a la derecha de este contínuum, la mayoría de estas formaciones prefieren ubicarse como una tercera vía o un tercer posicionamiento entre izquierda y derecha (objetivo que ya reivindicaba el fascismo) ${ }^{20}$. Por este motivo, para ubicar estos partido es muy útil usar la escala combinada de opiniones de expertos Lubbers, siendo 0 la posición más a la izquierda y 10 la más a la derecha. En dicha escala, los partidos de extrema derecha y los de la nueva derecha radical son los que obtienen una puntuación igual o mayor de 8,0 puntos (ver Tabla 1).

b. Criterio ideológico (referencias al fascismo clásico). Para Ignazi, los partidos deben tener vínculos con el fascismo clásico para cumplir dicho criterio. En el ámbito europeo, las formaciones de la "nueva extrema derecha" no reivindican, por estrategia o convencimiento real, al fascismo histórico (Partido de la Libertad en Austria, Vox en España, Frente Nacional en Francia o Partido por la Libertad de los Países Bajos). En cambio los partidos de la "vieja extrema derecha" (neonazis o neofascistas) se muestran nostálgicos a los principios míticos e ideológicos del fascismo, prueba de ellos son Amanecer Dorado

20 Por ejemplo, en España, Vox se define como "movimiento patriótico", y coloquialmente como "derecha desacomplejada" o "derecha no cobarde"; otro partidos como España2000 reivindican el "tercer posicionamiento", es decir no se ubican ni en la izquierda ni en la derecha. Incluso, algunos grupos, sin posicionarse como "zquierda transformadora", sí son capaces de beber de cierto lenguaje revolucionario de está o añadir el componente de la justicia social como eje vertebrador ideológico, son prueba de ello la hedillista Falange Auténtica o el nacional-bolchevique Movimiento Social Republicano (partido disuelto en la actualidad). 
en Grecia o Casa Pound en Italia o el Partido Nacional Demócrata Alemán (NPD). En España, el alzamiento del dieciocho de julio es defendido por la extrema derecha vinculadas al falangismo o/y franquismo. Además, existen un número significativo de grupos o formaciones minoritarias, como Alianza Nacional u Hogar Social, claramente identificados con el fascismo histórico.

c. Criterio actitudinal-sistémico (actitud ante el sistema político de forma global). Según Ignazi, estos partidos deben manifestar postulados antisistémicos para cumplir este criterio. De hecho, estos partidos son partidos "anti", por tanto suelen tener un discurso negativo, por ejemplo anti-pluralismo o antiparlamentarismo en el caso de la "vieja extrema derecha" y anti-establishment o anti-élites en el caso de la "nueva extrema derecha" (nueva derecha radical).

Siguiendo la terminología del académico italiano, un partido es de extrema derecha si, al menos, cumple el primer y también el tercer criterio, es decir si es "antisistema", definido este concepto, por Giovanni Sartori (1976), como el partido o grupo que muestra oposición al sistema político en sí mismo.

Según sea su posicionamiento en el segundo criterio, el profesor italiano diferenciará entre "extrema derecha tradicional o vieja extrema derecha", vinculada directamente al fascismo, y "extrema derecha postindustrial" o "nueva extrema derecha", que reniega del fascismo histórico (Ignazi, 2003).

Está división es similar a la que hemos explicado de Mudde entre partidos "extrema derecha" y "nueva derecha radical o derecha radical populista". Sin embargo siguiendo al profesor holandés, podemos matizar el tercer criterio que hemos comentado, distinguiéndolo en ambas corrientes, ya que la derecha radical populista es "(nominalmente) democrática, aunque se oponga a algunos valores fundamentales de las democracias liberales, mientras que la extrema derecha es en esencia anti-democrática, al oponerse al principio fundamental de soberanía del pueblo"(Mudde, 2007: 31).

Del mismo modo, Rodríguez Jiménez nos describe esa separación entre estas dos corrientes o familias de partidos:

"Debemos partir de la base de que los partidos de extrema derecha y ultranacionalistas que ocupan en la actualidad un lugar destacado en los medios de comunicación no abogan por la supresión de las instituciones y las libertades democráticas. Y que esa era una de las principales demandas del viejo extremismo y del fascismo, que hablaba de sacrificar los derechos individuales en beneficio de la colectividad, de la nación, del pueblo o de la raza. Señalemos, en segundo lugar, que en la nueva extrema derecha tiende a desaparecer la conexión con el legado del fascismo y el nazismo"(Rodríguez Jiménez, 2006: 94) ${ }^{21}$.

Otra clasificación interesante en que podemos fijarnos, es la que realiza Sabrina Ramet (Ramet, 2010: 24) dividiendo a estas formaciones en cinco grandes grupos ideológicos: ultranacionalistas, fascistas y criptofascistas, clericales, ultraconserva-

21 Del mismo modo, es de gran interés la clasificación de Rodríguez Jiménez (2006: 91) de los movimientos extremistas y radicales de derechas antes de la Segunda Guerra Mundial, donde encontramos dos grandes grupos, el fascismo y la extrema derecha, dividiendo esta última corriente en tres grandes familias de partidos: tradicionalistas, derecha autoritaria y derecha radical. 
dores y radical-populistas. Aunque su análisis queda marcado a los países del centro y este de Europa, es importante tenerlo en cuenta.

Igualmente, es reveladora la clasificación de Rodríguez Aguilera sobre el grado de euroescéptico de los partidos políticos: 1) Euroescépticos negativos y Eurófobos (o anti-Unión Europea): muestran críticas globales tanto al proyecto comunitario y como a las políticas concretas (toda la extrema derecha y buena parte de la nueva derecha radical se encontraría en este posicionamiento, como el Frente Nacional Francés, el Partido de la Libertad de Holanda o la Liga Norte); 2) Eurocríticos: están de acuerdo con el principio comunitario pero critican las políticas actuales de la Unión (pocos partidos de nueva derecha radical entrarían en este apartado que sería más próximo a las formaciones de izquierda radical como Syriza o el Bloco de Esquerda de Portugal); 3) Resignados o Europragmáticos: rechazan el proyecto de la Unión Europea, como tal, pero apoyan las vigentes políticas comunitarias necesarias para conseguir fondos de cohesión, vitales para el desarrollo económico de sus países (partidos conservadores, agrarios y derecha radical populista de Europa central y oriental como el Partido de la Gran Rumanía), y por otros motivos a los esgrimidos, más ideológicos y estratégicos, también incluimos en este grupo al Partido de la Libertad de Austria (Rodríguez-Aguilera de Prat, 2012: 55-56 y 169-170).

Por tanto, podíamos señalar diferencias entre los partidos de la nueva derecha radical: bastantes partidos piden la salida de la Unión Europea exigiendo un referéndum sobre la pertenencia de sus países a dicha organización (Frente Nacional); otros se muestran contrarios a ceder más soberanía pero están favor de la permanencia (Partido de la Libertad de Austria o Vox); y otros apoyan la integración pero de manera momentánea e instrumental o muestran ambigüedad en este tema (Liga Norte) ... Pero es cierto que, a veces los límites entre las dos opciones se reducen, y en muchas ocasiones, la posición de estas formaciones puede ser en algunos casos cambiante (Demócratas de Suecia ${ }^{22}$ ), haciendo difícil, por tanto, tal diferenciación.

En consecuencia, no toda la nueva derecha radical sostiene la misma visión euroescéptica, pero a pesar de ciertas divergencias, toda la nueva derecha radical muestra homogeneidad en algunos asuntos europeos: defensa de las raíces cristianas de Europa frente a la "islamización del continente", crítica a la creación de un superEstado federal europeo, oposición a la adhesión de Turquía y reprobación a tratados de mayor integración política como el de Lisboa, defensa de la primacía de la soberanía nacional sobre la Unión y apuesta por el cierre de fronteras europeas frente a la inmigración ilegal.

\section{Nación étnica según la nueva derecha radical y la extrema derecha}

La conceptualización de la nación desde la óptica de la extrema derecha y la nueva derecha radical es fundamental para nuestra investigación, ya que como veremos plasma una visón antagónica con una sociedad multicultural y, por consiguiente, cuestiona un pilar básico de las sociedades democráticas modernas.

22 En 2018, Demócratas de Suecia (DS) ha pasado de apoyar la salida de su país de la Unión Europea, a pedir una reforma de la misma. Hasta este año era partidario de un "swexit", a imitación del "brexit" británico, y de la celebración de un referéndum en Suecia sobre la "corrupta” UE. 
Siguiendo la clasificación de Michael Keating (1996) vamos a diferenciar entre "nación étnica" y "nación cívica", distinción muy similar a la división de Andrés de Blas Guerrero (1994) entre "nación cultural" y "nación política"; la división de Hans Kohn (1944) entre "nación oriental" (fundamentada en el romanticismo alemán ius sanguini) y "nación occidental" (basada en la Ilustración); o el contraste de Alain Renault (1991) entre la "nación organicista" frente a la "nación voluntarista".

La diferencia primordial es la siguiente: en la nación étnica "la pertenencia a la comunidad nacional se confiere basándose en criterios atribuibles"(Keating, 1996: 14) por tanto, no es elegible ni voluntaria, se pertenece a la nación si se cumple una serie de condicionantes culturales de ese territorio. Por otro lado la nación cívica "tiene sus orígenes en la aquiescencia individual (...) Cualquiera puede entrar a formar parte de la nación independientemente de su cuna o de sus orígenes étnicos", por tanto los individuos se constituyen voluntariamente y libremente en la colectividad, y por tanto "no hay ningún mito relativo a la ascendencia común" (Keating, 1996: 16).

En el siglo XIX, en el apogeo de nacionalismo y del romanticismo, era frecuente describir la condición étnica identificándola con poco rigor con el término "raza". Sin embargo, los fascismos recalcarán clara y conscientemente un nacionalismo racial, sobre todo en el caso del nacional socialismo alemán y en la Italia fascista, fundamentalmente desde 1938 con la instauración de las leyes raciales y posteriormente en la República Social Italiana, República de Salón.

Para la extrema derecha y las formaciones actuales de esta corriente (neofascistas o neonazis) el componente racial de la nación étnica todavía está presente, por tanto la extrema derecha enlazará los tres elementos: nación, etnia y raza. Esto se aprecia claramente por ejemplo en los discursos de Amanecer Dorado, de Casa Pound o del Partido Nacional Demócrata Alemán. En España, el partido nacional socialista Alianza Nacional sería uno de los grupos organizados más significativos (aunque ciertamente muy minoritario) que muestra postulados racistas sin ninguna ambigüedad. Además, grupos como Falange Española, Hogar Social, la Asociación Cultural de Amigos de León Degrelle o el ya disuelto Movimiento Social Republicano ${ }^{23}$ manifiestan importantes elementos raciales en su discurso político.

En esta defensa de una visión racial de la nación, también, podríamos citar otros pequeños partidos de extrema derecha, fascistas o nacional socialistas marginales, grupos ciberfascistas y movimientos callejeros como "skinheads white power" (HammerSkin), normalmente anclados en la intimidación y la violencia.

Sin embargo, la nueva derecha radical ha abandonado el empleo del término "raza", reivindicando la nación étnica y por tanto alegando la necesidad de la "diferenciación étnica” de los pueblos. Por tanto, los partidos políticos de nueva derecha radical defienden un nacionalismo étnico donde la pertenencia a la nación no es algo voluntario, es decir se pertenece a una nación si uno cumple una serie de condiciones étnicas, es decir una serie de rasgos culturales "propios" de esa nación: idioma, religión, historia, costumbres, gastronomía, conmemoraciones, festividades, arte, vestimenta... Y por supuesto, habría que añadir a estos elementos un competente genético relativo a la descendencia común. De este modo, solamente será parte de la nación

23 Del mismo modo, en España existieron históricamente un gran número de minúsculos movimientos fascistas o nacional socialistas: como Círculo Español de Amigos de Europa (CEDADE), Bases Autónomas, Juventudes Nacional Revolucionarias, Joven Nación o Alianza por la Unidad Nacional. 
quien tenga estos condicionantes étnicos, por ende, la nueva derecha radical rechazará cualquier construcción nacional basada en los principios de la nación cívica multicultural, aceptando solo la inmigración legal de minorías asimilables que puedan cumplir los condicionantes étnicos. La extrema derecha, como hemos visto, restringe aún más el concepto de nación y reclama la expulsión de todos los extranjeros a los que acusan de "contaminar la raza".

Esta defensa de la nación étnica la apreciamos por tanto, en todos partidos de la nueva derecha: Partido de la Libertad de Austria, Interés Flamenco, Liga Norte, la Unión Democrática de Centro de Suiza, Partido por la Libertad de Holanda, Verdaderos Finlandeses, Frente Nacional francés... En España en esta corriente nos encontramos a partidos como España2000 (López Ortega, 2016), Plataforma Per Catalunya (Casals, 2009). También es importante citar al partido liderado por Santiago Abascal, Vox, fenómeno en reciente auge y todavía hoy en estudio y análisis.

Profundizando en el concepto, podemos caracterizar a este etno-nacionalismo, defendido por la extrema derecha y la derecha radical populista, como "primordialista", esto es, la nación es algo inmutable en la historia, no varía su esencia o ideal ("nación esencialista o idealista"). Efectivamente, esta nación es un fenómeno persistente y recurrente en todas las épocas, por tanto es "perennialista", como nos relata Anthony Smith (Smith, 2001: 60).

El profesor de la London School of Economics nos muestra las características de esta concepción diferenciándola a una noción "moderna". La "nación perennialista" es una comunidad etno cultural, persistente e inmemorial, con raíces temporales y en el espacio (patria histórica), orgánica, sin fisuras ni diferencias, unitaria, con una única voluntad y ancestral. Por contrario, la "nación moderna" contradice la anterior, definiéndose como comunidad política, nueva, inconstante, mutable, creada, espontánea, dividida en grupos y de voluntades múltiples (ver Tabla 2).

Tabla 2. Diferencia Nación étnica perennialista y nación cívica moderna

\begin{tabular}{|c|}
\hline $\begin{array}{c}\text { Nación étnica } \\
\text { perennialista }\end{array}$ \\
\hline Cultural \\
\hline Persistente \\
\hline Raíces históricas \\
\hline Orgánica \\
\hline Unitaria \\
\hline Voluntad única \\
\hline Ancestral \\
\hline
\end{tabular}

\begin{tabular}{|c|}
\hline $\begin{array}{c}\text { Nación cívica } \\
\text { moderna }\end{array}$ \\
\hline Política \\
\hline Inconstante \\
\hline Creada \\
\hline Espontánea \\
\hline Dividida en grupos \\
\hline Voluntades múltiples \\
\hline Nueva o mutable \\
\hline
\end{tabular}

Fuente: Elaboración propia a partir de Smith (Norris, 2009: 74-77).

Por tanto, la derecha radical y la extrema derecha para promover esta nación étnica busca la unidad y homogeneidad cultural, rechaza así cualquier elemento que le puede ser dañino a la misma, identificando la inmigración como "invasiva", rompedora de la identidad nacional e incapaz de asimilarse, obviamente no se cree en la 
integración multicultural. De todas formas, en este punto también vemos diferencias entre la extrema derecha y la nueva la derecha radical. La primera rechaza toda emigración tanto la legal como la irregular. "Los neofascistas pugnan por conservar esta comunidad nativa (...) mediante la expulsión de todos los extranjeros (legales e ilegales) y el rechazo sistemático hacia minorías como los homosexuales o los gitanos" (Olascoaga, 2018: 8-9), por su parte "la derecha radical populista se pronuncia en contra de los elementos no nativos, pero solo se enfoca en expulsar exclusivamente a la inmigración ilegal, dejando una puerta abierta para todos los extranjeros y minorías étnicas cuyo deseo sea integrarse en la nación receptora" (Olascoaga, 2018: 9).

Asimismo, la nueva derecha radical hace hincapié en el rechazo a la comunidad musulmana. De hecho, una de las diferencias de los partidos neofascistas con la nueva derecha radical será que los primeros manifiestan un claro anti-judaísmo ${ }^{24}$ frente a la derecha radical populista que es, unánimemente, islamófoba. Aquí vemos también la diferencia entre lo étnico, que defiende la nueva derecha radical y la étnica racial que defiende la extrema derecha, aunque en ciertos grupos la distancia se puede difuminar. La nueva derecha radical ha sabido usar fenómenos como el aumento de la inmigración musulmana, la llegada de refugiados o el terrorismo islámico para construir una argumentación islamofóbica y tener un cierto apoyo de sectores de la población autóctona temerosos del fenómeno.

\section{Palingenesia ultranacionalista según la nueva derecha radical y la extrema derecha}

La nación étnica, que acabemos de analizar, debemos complementarla con el concepto de Roger Griffin. El politólogo británico usa por primera vez en 1991 el término "palingenesia" para referirse a una característica del nacionalismo propia del fascismo (y por tanto de la extrema derecha) y que podemos extrapolar a la nueva derecha radical, con alguna diferencia que veremos. El concepto "ultranacionalismo palingenésico" deviene de la aspiración del renacimiento de un pasado glorioso mitificado, es decir, se trata de resucitar o hacer resurgir hitos históricos ideales o utópicos. Dicha reencarnación nacional es necesaria, según el fascismo, para superar la decadencia en la que se había sumido la nación. De esta forma, se define el fascismo como "una ideología política cuyo núcleo mítico, entre sus distintas permutaciones, radica en que es una forma palingenésica de ultranacionalismo populista" (Griffin, 2010: 26) ${ }^{25}$.

Para el profesor británico, el mito palingenésico critica la modernidad y representa un regreso a una Edad de Oro en la historia del país, y para conseguir el renacimiento de la nación del "declive", "decadencia", "hundimiento", "oscuridad", "ocaso", "ruina", "ruptura", "muerte", "crepúsculo" o "destrucción" en el que está sumida. Todos estos términos son usados, tanto por el fascismo (extrema derecha) como por la nueva derecha radical, para definir el estado de "descompo-

\footnotetext{
24 La derecha radical populista no solo no muestra antisemitismo sino que algunos partidos de esta corriente se muestran como grandes valedores del Estado de Israel (Vox o Partido de la Libertad de Austria).

25 Para profundizar más sobre este concepto en el fascismo histórico, en Italia bajo el poder de Mussolini y en Alemania baja el mando de Hitler, ver otro relevante libro del mismo autor (Griffin, 2010).
} 
sición" de la nación. Aunque este concepto puede ser propio de cualquier ideología ${ }^{26}$, el fascismo (extrema derecha) y la derecha radical populista, como veremos, son los únicos que se centran fuertemente en el precepto mítico. De esta forma, esta ideología llama a una reconstrucción nacional, a una recuperación espiritual que ensalza el pasado como fundamento de inspiración para la resurrección de la nación:

"El fascismo es una forma de ideología de extrema derecha que celebra la nación o la raza como una comunidad orgánica que trasciende todas las otras lealtades. Enfatiza el mito del renacimiento nacional o racial después de un período de decadencia o destrucción. Con este fin, el fascismo llama a una revolución espiritual contra los signos de la decadencia moral como el individualismo y el materialismo, y trata de purgar las fuerzas extrañas y grupos que amenazan a la comunidad orgánica (...) el fascismo a menudo idealiza el pasado como fuente de inspiración para el renacimiento nacional"(Griffin, 2012: 7)

El nacional socialismo alemán imaginaba la resurrección espiritual de la nación a través de la recreación de otro Imperio germano. El III Reich pretendía resucitar el I Reich, el Sacro Imperio Romano Germano (800-1806) fundado por Carlomagno (que a su vez se llamaba continuador del Imperio Romano) y el II Reich (o Imperio Alemán) de Otto Von Bismarck, que duró desde 1871 hasta 1918. Además son muy significativas las referencias mitológicas a héroes, dioses nórdicos, a la leyenda... De esta forma, el nazismo rechazaba lo moderno en todas sus manifestaciones, como en el arte moderno definido como "decadente". Y frente a este arte "degenerado", el nacional socialismo encumbraba la obra de arte total, continuando la visión del romanticismo y los principios wagnerianos contrarios a la "disolución tan deplorada del arte griego". Por consiguiente, se ensalza lo legendario, porque "la leyenda, sean cual fueren la época y nación a la que pertenezca, tiene la ventaja de comprender exclusivamente lo que ésta época y ésta nación tiene de puramente humano y presentarlo bajo una forma original señaladísima y por lo tanto inteligible a primera vista" (Wagner, 1908) ${ }^{27}$.

Y por supuesto, encontramos la mitificación y glorificación de la guerra, la fortaleza, la disciplina, la lucha, el ejército y por supuesto de la propia violencia frente a la razón. El líder nacional socialista alemán lo describe así: "Día tras día pude replicar a mis contradictores (...) hasta que en un momento dado debió ponerse en práctica aquel recurso que ciertamente se impone con más facilidad que la razón: la violencia"(Hitler, 1925).

Por su parte, el fascismo italiano proponía restaurar el ideal del Imperio Romano. Esto lo vemos reflejado claramente en su simbología, iconografía y estética copiada de dicho periodo ${ }^{28}$. Asimismo Mussolini se siente continuador de Garibaldi, líder de

26 Efectivamente, el concepto se puede aplicar también en otras ideologías no vinculadas al fascismo o a la nueva derecha radical, como es el caso de Israel, que manifiesta un claro ultranacionalismo palingenésico (Lerín Ibarra, 2018)

27 Para más información, sobre la relación entre Wagner y el nacional socialismo, leer el artículo de Enric Riu (Riu, 2013: 26)

28 Citemos algunos ejemplos: águilas imperiales, saludo romano, edificaciones, urbanismo y gran variedad de elementos arquitectónicos (como los arcos triunfales). Además, se marca una férrea disciplina artística imitando los estilos imperiales romanos. 
la Unificación Italiana del siglo XIX, y creador del "movimiento camisas" con sus "camisas rojas" imitada por "el Duce" en sus "camisas negras"(Payne, 1982: 56).

También, apreciamos la apología y mitificación de la violencia que hemos observado en el nacional socialismo. Por ejemplo, el artista futurista e ideólogo fascista Marinetti (2009) ensalza la "necesidad y belleza de la violencia" apoyando "la fuerza sanadora de la guerra" como elemento básico del progreso. De este modo, se defiende la idea futurista de la "violencia saludable" y se justifica la destrucción necesaria para la edificación de un nuevo mundo.

La idea de palingenesia va ligada al concepto de decadencia del momento presente del que hay que emerger para rescatar ese "glorioso pasado de la patria". Como el profesor Miguel Ángel Simón Gómez (2007) nos relata, en esta idea de decadentismo y decadencia, el fascismo, la actual extrema derecha y en parte la nueva derecha radical van a beber intelectualmente de pensadores y autores como Carl Schmitt (2014), Ernst Von Salomon (1966), Oswald Spengler (1923) o Ernst Jünger (2005).. Para estos autores, la decadencia del mundo moderno es un factor natural, no lo ven como una catástrofe sino como algo necesario para conseguir tras ella la reencarnación de la esencia de la gran nación. Además, defenderán la vuelta a la espiritualidad, rechazarán la idea ilustrada de razón y criticarán la modernidad. Exceptuando la aceptación de la técnica (Marinetti, 2008), se rebelarán contra todo lo que significa el "mundo moderno" y contra uno de sus representantes: el habitante de la ciudad: "un nuevo nómada, un parasito, el habitante de la gran urbe, hombre puramente atenido a los hechos, hombre sin tradición, que se presenta en masas informes y fluctuantes (...) un paso gigantesco hacia lo inorgánico, hacia el fin" (Spengler, 1923: 66).

Tras el final de la Segunda Guerra Mundial y la derrota de los fascismos, los pequeños partidos de extrema derecha, prácticamente irrelevantes, continuaran reclamando el renacimiento de un pasado glorioso mitificado heredero de una etapa "imperial" o la resurrección de una "poderosa nación" y manteniendo reivindicaciones del fascismo histórico. Por su parte, los partidos de la nueva derecha radical europea van a modificar algunos elementos ideológicos, como ya hemos comentado. No obstante, bastantes de los mitos palingenésicos se conservan. Se exhiben personajes y hechos heroicos (históricos o legendarios) como por ejemplo Juana de $\mathrm{Arco}^{29} \mathrm{o}$ "la Europa de Lepanto" contra el Islam. Es España, se puede claramente observar por parte de Vox la recuperación histórica de personajes o hechos mitificados como la "Reconquista", "Isabel la Católica", "El Cid", "la conquista de América", "Blas de Lezo" o "Don Pelayo". Además, en muchos casos se muestran reivindicaciones irrendentistas, de muestra citamos la "Gran Hungría", "la Gran Rumania" o la recuperación de Gibraltar en el caso español.

Sin embargo, en muchas formaciones europeas de derecha radical populista no hay una referencia a un hecho concreto a diferencia de la extrema derecha o de Vox que, como hemos visto, sí muestran reivindicaciones míticas mucho más específicas. En general, se critica el "pasado glorioso corrompido", "una edad de oro destruida", "tradiciones perdidas" o simplemente se apela un tiempo pasado mejor. La idea es sencilla, la esencia de la nación es pura y es ahora cuando está "corrompida", "humi-

29 Juana de Arco es un ejemplo paradigmático. El Frente Nacional Francés se moviliza cada primero de mayo reivindicado a la "madre de la patria francesa" y "luchadora contra la invasión extranjera". Esa imagen de batalladora contra el invasor extranjero, fue reivindicada por el régimen de Vichy y recuperada décadas más tarde por Jean-Marie Le Pen. 
llada" o "destruida". Por tanto, el presente es decadente y la nación debe volver a su grandeza del pasado. Por otro lado, la derecha radical populista no muestra la mitificación de la violencia que observábamos en el fascismo y que conserva la actual extrema derecha.

Hay un concepto que los nuevos partidos de extrema derecha y la nueva derecha radical comparten ahora. La misma idea de "Europa" y sus raíces étnicas y cristianas son en sí mimas referencias míticas a recuperar, llegando, incluso, a reivindicarse un "Imperio Europeo" (Benoist). El catedrático de ciencia política Joan Antón-Mellón (2004) nos habla de "mito unificador transnacional Europa", de esta forma, "el viejo nacionalismo se disolvía en un concepto superior racial y etnocrático de base más biológica que cultural". Profundizando, habría que añadir que se reivindica una Europa sin heterogeneidad racial en el caso de la extrema derecha y una Europa homogénea étnicamente en el caso de la derecha radical populista.

Sin embargo, ni la extrema derecha ni la mayoría de la nueva derecha radical asumen la idea de la Unión Europea actual que según estas formaciones conduce a un súper-Estado federal europeo, centralizador, hiperreglamentista, amenazador de la nación étnica y permisivo con la emigración. En cambio, sí defienden una idea de "Europa de las patrias" respetuosas con las soberanías nacionales, una Europa étnica "de raíces cristianas" contraria al multiculturalismo (derecha radical populista) o una "Europa blanca" racialmente homogénea (extrema derecha).

Precisamente, Rodríguez-Aguilera de Prat (Rodríguez-Aguilera de Prat, 2012: 72) nos recuerda que: "la derecha radical reivindica un cierto diferencialismo de Europa en el mundo, de ahí sus referencias míticas a este espacio como comunidad de étnicas y como madre patria de naciones civilizadas. Hay, por tanto, un cierto mito de Europa en la derecha radical contemporánea que arranca de los fascismo clásicos que aspiraron a un nuevo orden". Por tanto, la derecha radical populista reivindica un pasado mítico palingenésico heredero del fascismo, y por tanto de la extrema derecha, pero está vez de carácter étnico vinculado a la idea de la recuperación de una civilización cristiana y occidental frente a otras, especialmente la islámica (xenofobia e islamofobia).

La ideológica de la nueva derecha radical va a beber de los planteamientos palingenésicos de la Nueva Derecha de Charles Champetier y Alain de Benoist (GRECE). Esta corriente de pensamiento defienden la teoría del etnocentrismo y la diferenciación, con la pretensión de rehusar cualquier relación con los fascismos (vinculados a la extrema derecha), acogiendo, incluso, el concepto de hegemonía cultural de Antonio Gramsci. Sin embargo, Roger Griffin afirma que "la Nueva Derecha conservaba gran parte de las bases míticas y de los planteamientos míticos causales del fascismo, pese a las extensas alteraciones y redecoraciones estructurales que llevo a cabo en el visible edificio ideológico"(Griffin, 2000: 217). De hecho, Joan Antón-Mellón (Antón-Mellón, 2011: 91) sentencia que la Nueva Derecha es una forma más sofisticada de ideas del fascismo.

"El fascismo se convirtió en una ideología maldita, criminalizada jurídicamente salvo por unas escasas minorías de creyentes y/o simpatizantes - obviamente los oportunistas desaparecieron-. Esta situación de alejamiento máximo del poder hizo que cobrara una relevancia superior la conservación de las ideas-fuerza que homogenizaron a la Derecha Radical en el primer tercio del siglo veinte. 
Esta ha sido la muy complicada labor que la ND se impuso reconvertir dichas ideas-fuerza adaptándolas a una época de predominio indiscutido de las ideas y valores democráticos. Una adaptación necesariamente sofisticada ya que, para que perviva lo estratégico, era necesario desprenderse de lo táctico. Una identidad no idéntica disfrazada de nuevo paradigma más allá de la derecha y de la izquierda".

\section{Reto a la gobernanza y a la calidad de la democracia}

La extrema derecha o "vieja extrema derecha" (Ignazi, 1992) actual tiene un papel residual e irrelevante en el panorama europeo, con nula o escasa representación, excepto el caso de Grecia donde sí encontramos un partido, Chrysí Avgí, Amanecer Dorado, con las características propias de extrema derecha con un porcentaje electoralmente relevante. Prueba de ello es el 9,4\% de votos que obtuvo el partido de ideología nacional-socialista en las elecciones al Parlamento Europeo de 2014 o el $7 \%$ que consiguió en las elecciones parlamentarias griegas de 2015. Dicho partido es antipluralista, defiende una idea racial ${ }^{30}$ de la nación, comparte los mitos palingenésicos fascistas y tiene claros vínculos ideológicos con el nazismo, por lo cual supone un riesgo total no solo a la gobernanza sino al propio sistema democrático.

En el resto de Europa, no vemos a partidos de esta corriente de pensamiento con relevancia política, por lo que el riesgo de estos partidos para la gobernanza y la calidad democrática se atempera o no existe.

Por su parte, la nueva derecha radical, como hemos comentado, se ha extendido por prácticamente toda Europa, hecho que le hace merecedor de un análisis sosegado. Su defensa del etnonacionalismo y el ultranacionalismo palingenésico supone una crítica a la modernidad y a la multiculturalidad, por tanto provoca el cuestionamiento de los cimientos del sistema democrático actual o por lo menos a la concepción de la democracia cívica moderna, que tiene como uno de sus pilares el pluralismo social y político. Aunque no son teóricamente antidemocráticos como los partidos de extrema derecha, la derecha radical populista tiene una visión utilitaria de la democracia. Como nos recuerda el profesor de Ciencia Política, Cesáreo RodríguezAguilera de Prat (Rodríguez-Aguilera de Prat, 2012: 65), los partidos de derecha radical tienen "una concepción instrumental/ funcional de la democracia".

La construcción de teorías políticas basadas en concepciones étnicas de la nación y en mitos palingenésicos suponen una evidente quiebra del pluralismo democrático. La extrema derecha y la nueva derecha radical postulan que cada nación pertenece a una específica etnia (y raza en el caso de la extrema derecha), con una cultura homogénea, justificando así el uso exclusivo del territorio por la misma y la expulsión o segregación de etnias "ajenas" a la nativa.

Un principio básico de la democracia moderna es que esta permite el gobierno de la mayoría pero con respeto de las minorías, sin embargo la nueva derecha radical y la extrema derecha cuestionan la diversidad cultural de la sociedad y el hecho mismo

30 Uno de los principios básico de la ideología de Amanecer Dorado es la raza o la "sangre", como el propio partido expresa, ensalzado un "raza helénica" constreñida ante la "invasión racial del extranjero". Al mismo tiempo, en las concentraciones de Amanecer Dorado se exclaman lemas como "Sangre, Honor, Amanecer Dorado o "Sangre y Honor", consignas de las SS (Schutzstaff) de la Alemania nazi. 
de que existan minorías étnicas en la misma, enfrentándose radicalmente a cualquier proceso de integración multicultural. Su apuesta por la homogeneidad sociocultural ataca por tanto la esencia misma de una democracia basada en los principios de la nación cívica.

Efectivamente, incluso, aunque no hayan conseguido una mayoría absoluta en las elecciones que les permita desplegar todo su proyecto político, el crecimiento de la nueva derecha radical en Europa representa un peligro y una amenaza a la gobernanza y a la calidad de la democracia. El reto, como vamos a ver, es doble. Por un lado, otras formaciones, sobre todo partidos de ideología liberal-conservadora o centro derecha, pueden copiar o reproducir su discurso en buen grado queriendo recuperar el electorado perdido, especialmente en materia migratoria. Por otro lado, existe el riesgo de que estos partidos, coparticipando en gobiernos de coalición como ya ocurre en Italia, Suiza, Holanda o Austria, asuman parte de poder político para implementar su programa electoral, poniendo en pie sus duras políticas contrarias a la emigración, a los refugiados y fomentando un claro euroescepticismo que en muchos países ya tiene un gran calado popular.

Este aumento del euroescepticismo alentado por la nueva derecha radical es un hecho real que nos muestra un cuestionamiento a la gobernanza democrática europea: "la oposición a más integración europea expresa rechazos y/o dudas sobre la capacidad de la UE de asegurar efectivamente beneficios materiales, sobre la viabilidad de una genuina gobernanza democrática europea y sobre los riesgos para la identidad nacional. En este sentido, se teme por el futuro del estado de bienestar por la pérdida de control popular y de calidad democrática" (Rodríguez-Aguilera de Prat, 2012: 40).

Por su parte, la extrema derecha es contraria íntegramente a la Unión Europea, aunque sí reconoce la importancia de la unidad de los pueblos europeos unidos por vínculos raciales, apostando así por una "Europa blanca" o racialmente homogénea. Sin embargo, como hemos comentado antes, su poca relevancia política, salvo el caso heleno, hace que sus postulados no supongan a día de hoy un riesgo o reto democrático.

Al mismo tiempo, el carácter populista de la nueva derecha radical es uno de los elementos que lo diferencia de la extrema derecha, que elude este posicionamiento o estrategia política. El populismo es el reflejo, también, de una crítica a la política convencional y manifiesta hechos evidentes que muchos ciudadanos perciben. Las críticas de estos partidos a la "élite política", al "establishment", a la "política tradicional corrupta" se debe a un alejamiento real de los dirigentes y partidos políticos convencionales que se han distanciado de las demandas de buena parte de la población. Por esto, corresponde "a los demócratas reaccionar y exigir una democracia de mayor calidad y a los dirigentes de los partidos con sincera vocación democrática acercarse más a los ciudadanos" (Rodríguez Jiménez, 2006: 98).

Conjuntamente, hay que añadir una variable socioeconómica en el análisis. Los partidos de nueva derecha radical, no así la extrema derecha, han crecido en las últimas décadas aprovechando un contexto y una situación socioeconómica complicada en grandes capas de la población. La crisis económica, las reformas laborales y los recortes sociales (sobre todo en educación y sanidad) han dañado gravemente a sectores populares que ven peligrar su "status quo". Los trabajadores manuales y también las clases medias "perciben los cambios con recelo o con miedo, pues sienten que su posición social mejor o peor, es vulnerable” (Rodríguez Jiménez, 2006: 97). 
Dicha rebaja de bienestar social, o miedo a perderlo, ha hecho que buena parte de estás capas sociales apoyen ahora a estos partidos de nueva derecha radical que culpan a las minorías étnicas de "aprovecharse del Estado de Bienestar" y reclaman la "preferencia nacional" en derechos sociales, económicos y laborales. Por tanto, está precarización laboral y está perdida de nivel socioeconómico de grandes sectores de la población favorece al ascenso de la derecha radical. Por tanto, corresponde a los "demócratas" revertir los recortes en los derechos sociales y laborales para que la prosperidad se expanda a las clases medias y populares para evitar así que existan conflictos por los servicios sociales y recursos públicos. Por consiguiente, se debe incrementar el gasto social, mejorar la sanidad y la educación, avanzar en la protección laboral, mejorar las políticas de inclusión social y en definitiva, perfeccionar el Estado de bienestar para todos los ciudadanos que habitan el país.

\section{Conclusiones}

En este trabajo, hemos profundizado en la conceptualización de la nueva derecha radical diferenciándola de la extrema derecha mediante un análisis comparativo entre ambas corrientes con un estudio de sus componentes ideológicos. De esta forma y siguiendo esta metodología, hemos investigado dos principios teóricos de estos partidos que suponen un riesgo para la gobernanza democrática: la defensa de la nación étnica y la palingenesia ultranacionalista.

Por tanto, después de nuestro análisis, podemos concluir que la extrema derecha y la nueva derecha radical son corrientes de pensamiento diferentes. Lo cual se puede apreciar en los siguientes aspectos.

La extrema derecha defiende una concepción de nación étnica racial frente a la nueva derecha radical que tiene una visión étnica de la nación sin componente racial. Ambos comparten su rechazo a la nación cívica, basada en la voluntad política. Relacionado a esta concepción, la nueva derecha radical es contraria a la inmigración ilegal aceptando la emigración legal que comparta los principios étnicos de los nativos, en cambio la extrema derecha rechaza tanto la inmigración ilegal como la legal, reivindicando su expulsión en ambos casos.

Por otro lado, la extrema derecha tiene vínculos claros o reivindica el fascismo tanto en sus preceptos míticos como ideológicos. En cambio, la derecha radical populista rechaza o no muestra relación con el fascismo clásico o histórico.

Asimismo, la extrema derecha defiende una "Europa blanca" o racialmente homogénea, la nueva derecha radical apoya la "Europa de las patrias" étnicamente homogénea. Además, la primera rechaza completamente la Unión europea, los partidos de derecha radical populista muestran posiciones euroescépticas pero en ocasiones de forma más ambigua, incluso algunos partidos (europragmáticos o euroresignados) apoyan políticas de cohesión europea para el desarrollo de sus países (Rodríguez-Aguilera de Prat, 2012).

Del mismo modo, los partidos de extrema derecha muestran referencias relacionadas a la palingenesia fascista e imperialista. Por su parte, los partidos de nueva derecha radical, normalmente, muestra una palingenesia ultranacionalista menos concreta y más genérica, adaptada a sus países. Además, estos últimos reivindican la idea de Europa de raíces cristianas como referente frente a otras civilizaciones que la ponen en "peligro" (islam). 
Otra diferencia clara es el carácter populista de la nueva derecha radical que no ostenta la extrema derecha. Este marcado populismo anti-establishment (anti élite política) es un elemento central de la derecha radical populista, por eso, estos grupos también reciben esta distinción en la nomenclatura que usamos para distinguirlos. La extrema derecha normalmente elude esta retórica, estrategia o posicionamiento político, estos grupos no critican solo la élite política gobernante sino al sistema en sí de forma integral.

De esta forma, la extrema derecha tiene una concepción política, heredera del fascismo, antisistema, antidemocrática, antipluralista y antiparlamentaria. En cambio, la derecha radical populista es teóricamente democrática, aunque algunos autores identifiquen que su noción sobre la democracia es "instrumental" (RodríguezAguilera de Prat, 2012: 62). Además, su concepto de la democracia queda constreñida, ya que promociona o da primacía a los nativos (preferencia nacional). Según Roger Griffin (2000), aceptan el sistema liberal pero piden la expulsión, marginación o segregación de las personas que no son de la étnica autóctona, es decir propugnan un "liberalismo etnocrático".

Finalmente, hemos analizado el riesgo a la gobernanza y a la calidad misma de la democracia que suponen estos grupos. La extrema derecha debido a su irrelevancia política no supone un riesgo democrático, salvo el caso heleno que hemos mencionado. Sin embargo, el crecimiento electoral de la derecha radical populista ha hecho aumentar su relevancia política en prácticamente toda Europa, lo que sí supone un grave riesgo a la calidad misma de la democracia, sobre todo por sus principios etnicistas y su ultranacionalismo palingenésico. Hemos visto un doble reto a la gobernanza democrática: por un lado, estos partidos pueden conseguir cuotas de poder donde puedan implementar sus políticas; y por otro lado, una posible "contaminación" de su discurso político en el propio sistema político.

\section{Bibliografía}

Antón Mellón, J. (2004). "La teoría política de la nueva derecha europea", en Claves de Razón Práctica, (143): 26-37.

Antón Mellón, J., Cabezas de Alcalá, S., Lara Amat y León, J., \& Velilla, J. (2011). “Inmigración y discurso electoral en las elecciones municipales de 2007 en Cataluña. Análisis de la similitud y divergencia en relación al discurso xenófobo de la derecha radical europea neopopulista", Crítica Penal y Poder, en 1: 69-87.

Antón-Mellón, J. (2011). "El eterno retorno. ¿Son fascistas las ideas-fuerza de la Nueva Derecha Europea (ND)?”, en Foro Interno, 11: 69-92.

Antón-Mellón, J., \& Hernández-Carr, A. (2016). "El crecimiento electoral de la derecha radical populista en Europa: Parámetros ideológicos y motivaciones sociales", en Política y Sociedad, 53: 17-28.

Backes, U., \& Jesse, E. (1984). Totalitarismus, Extremismus, Terrorismus. Opladen: Leske \& Budrich.

Bell, D. (1955). The new american right. Nueva York: Criterion Books.

Bell, D. (1963). The radical right. The new american right expanded and updated. Garden City, N.Y: Doubleday \& Company, Inc.

Betz, H.-G. (2004). La droite populiste en Europe: extrême et démocrate. Paris: Autrement. Biorcio, R. (1992). "El resurgimiento del populismo en Italia y Francia”, en Debats, 42: 11-16. 
Casals, X. (2009). La Plataforma per Catalunya: la eclosión de un nacional-populismo catalán (2003-2009). Barcelona: ICPS.

De Blás Guerrero, A. (1994). Nacionalismos y naciones en Europa. Madrid: Alianza Editorial.

De Lange, S., \& Mudde, C. (2005). "Political extremism in Europe", en European Political Science, 4, 476-488.

Decker, F. (2016). “¿De negro y rojo a negro y verde? Posibles coaliciones en Alemania, antes de las elecciones al Parlamento Federal en 2017”, en Sistema: Revista de Ciencias Sociales, 244: 129-143.

Griffin, R. (2000). "Plus ça change! The Fascist Pedigree of the Nouvelle Droite", en E. J. Arnold (Ed.), The Development of the Radical Right in France: From Boulanger to Le Pen. London: Palgrave Macmillan UK, pp. 217-252.

Griffin, R. (2010). Modernismo y fascismo. La sensación de comienzo bajo Mussolini y Hitler. Madrid: Akal.

Griffin, R. (2012). "Studying fascism in a postfascist age. From new consensus to new wave?", en Fascism, 1(1): 1-17.

Hernández-Carr, A. (2011). "La derecha radical populista en Europa: discurso, electorado y explicaciones”, en Revista Española de Investigaciones Sociológicas, 136 (1): 141-159.

Hitler, A. (1925). Mi lucha. Chile: Jusego.

Hoffman y otros, S. (1962). Le mouvement poujade. París: Editorial Colin.

Ignazi, P. (1992). “The silent counter-revolution”, en European Journal of Political Research, 22(1): 3-34.

Ignazi, P. (2003). Extreme right parties in Western Europe. Oxford: Oxford University Press. Jünger, E. (2005). Radiaciones I: Diarios. Barcelona: Tusquets Editores S.A.

Keating, M. (1996). Naciones contra Estado. Barcelona: Ariel.

Kohn, H. (1944). The idea of nationalism. A study in its origins and background. Nueva York: MacmiUan.

Lerín Ibarra, D. (2018). "Palingenesia: La nueva derecha radical y el Estado de Israel”, en El Viejo Topo, 366-367: 70-77.

López Ortega, A. I. (2016). "El discurso totalitario del partido político España 2000”, en Anduli Revista Andaluza de Ciencias Sociales, 16: 102-118.

López Ortega, A. I. (2017). España 2000, la evolución de la derecha radical valenciana (2003-2015). Tesis Doctoral. Universidad de Valencia. Recuperado de http://roderic.uv. es/handle/10550/59340 (Consultado, 3 de marzo de 2019).

Marinetti, F. T. (2008). Expresiones sintéticas del futurismo. Barcelona: Dvd Ediciones.

Marinetti, F. T. (2009). Necesidad y belleza de la violencia. Barcelona: Editorial Doble.

Mudde, C. (2007). Populist radical right parties in Europe. Cambridge: University Press Cambridge.

Norris, P. (2009). Derecha radical votantes y partidos politicos en el mercado electoral. Madrid: Akal.

Olascoaga, O. G. (2018, abril). "Presence of neo-fascism in contemporary european democracies”, en Revista Española de Investigaciones Sociológicas: 3-19.

Payne, S. (1982). El fascismo. Madrid: Alianza Editorial.

Ramet, S. P. (2010). Radical right in central and eastern Europe since 1989. Pensilvania: Penn State Press.

Raschke, J. (1983). I partiti dell'Europa occidentale. Roma: Ed. Riuniti.

Renaut, A. (1991). Logiques de la nation. In theories du nationalisme; Nation, nationalite, ethnicite, edited by Gil Delannoi and Pierre-Andre Taguieff. Paris: Editions Kime. 
Riu, E. (2013). “Wagner, Hitler y el nazismo”, en Le Monde Diplomatique, Marzo, 26. Recuperado en: https://mondiplo.com/wagner-hitler-y-el-nazismo (Consultado, 18 de septiembre de 2018).

Rodríguez Jiménez, J. L. (2006). "De la vieja a la nueva extrema derecha (pasando por la fascinación por el fascismo)", en Historia Actual Online, 9: 87-99.

Rodríguez-Aguilera de Prat, C. (2012). Euroescepticismo, eurofobia y eurocriticismo. Barcelona: Huygens Editorial.

Rydgren, J. (2005). "Is extreme right-wing populism contagious? Explaining the emergence of a new party family", European Journal of Political Research, 44(3): 413-437.

Salomon, E. Von. (1966). Los proscritos. Barcelona: Luis de Caralt.

Sartori, G. (1976). Parties and party systems: A framework for analysis. London: ECPR Press.

Schmitt, C. (2014). El concepto de lo político. Madrid: Alianza Editorial.

Simón Gómez, M. A. (2007). "El decadentismo en la derecha radical contemporánea", en Politica y Sociedad, 44 (1): 175-198.

Smith, A. D. (2001). Nacionalismo y modernidad. Madrid: Ediciones Istmo.

Spengler, O. (1923). Der Untergang des Abendlandes. München: Beck Verlag.

Taguieff, P. A. (2007). Interpretar la ola populista en la Europa contemporánea: entre resurgencia y emergencia. La extrema derecha en Europa desde 1945 a nuestros días. Madrid: Tecnos, pp. 39-66.

Wagner, R. (1908). Dramas musicales de Wagner. Tomo I Carta a Federico Villot. Barcelona: Casa editorial Maucci. 